\title{
KEBUTUHAN ARMADA DAN KESESUAIAN TARIF TAKSI KONVENSIONAL DI KOTA MATARAM BERDASARKAN BOK, ATP DAN WTP
}

\author{
I WAYAN SUTEJA ${ }^{1)}$, HASYIM ${ }^{2)}$, I GEDE PUTU WARKA ${ }^{3)}$ \\ Teknik Sipil Universitas Mataram \\ e-mail : ${ }^{1)}$ w.suteja@gmail.com, ${ }^{3)}$ igedeputuwarka@gmail.com
}

\begin{abstract}
ABSTRAK
Dengan berkembangnya teknologi maka berkembang pula pemikiran untuk menggunakan aplikasi dalam dunia usaha. Salah satunya adalah usaha dalam bidang transportasi. Saat ini sudah muncul layanan angkutan berbasis aplikasi. Munculnya layanan tersebut, maka Taksi Konvensional memiliki pesaing baru. Adanya persaingan tersebut, menyebabkan timbulnya perselisihan antara Taksi Konvensional dengan Taksi berbasis aplikasi. Adanya Taksi Berbasis Aplikasi, menyebabkan sebagian masyarakat di Kota Mataram berpeluang berpindah minat menggunakan Taksi Berbasis Aplikasi. Dengan kondisi tersebut maka jumlah armada dan kesesuaian tarif Taksi Konvensional di Kota Mataram perlu di tinjau ulang.

Dalam penelitian ini, diteliti tarif taksi sesuai dengan perhitungan biaya operasional kendaraan. Kemudian di bandingkan dengan kemampuan membayar dan kemauan masyarakat Kota Mataram. Kemudian akan dilakukan perhitungan jumlah kebutuhan armada taksi untuk Kota Mataram.

Dari Hasil penelitian dapat disimpulkan bahwa : 1). terjadi kelebihan jumlah armada taksi, yang optmal adalah 550 armada, tapi kenyataan Armada taksi yang beroprasi saat ini berdasarkan kondisi rill di lapangan adalah sebanyak 636 armada dari semua operator, 2). 48,75\% responden mempunyai kemampuan membayar tarif yang nilainya sebesar Rp.3.900/kilometer dan sisanya 52,25\% responden karena terpaksa menggunakan taksi konvensional,3). Tarip yang berlaku saat ini sudah sesuai dengan peraturan pemerintah. Hal ini dilihat dari perhitungan biaya operasional kendaraan (BOK) untuk tarif per kilometer adalah Rp 4.000,- per kilometer sedangkan tarif yang berlaku saat ini adalah Rp 3.900,- hanya selisih Rp 100,-
\end{abstract}

Kata kunci $\quad$ : ATP, WTP, BOK, Kebutuhan Armada Taksi, Tarif Taksi.

\section{ABSTRACT}

With the development of technology, the thinking to use applications in the business world also develops. One of them is a business in the field of transportation. At present an application-based transport service has emerged. The emergence of these services, the Conventional Taxis have new competitors. The existence of such competition has led to disputes between conventional taxis and application-based taxis. The existence of Application-Based Taxi, causing some people in the city of Mataram have the opportunity to switch interests using Application-Based Taxi. Under these conditions, the number of fleets and the suitability of conventional taxi rates in the city of Mataram need to be reviewed.

In this study, examined taxi rates according to the calculation of vehicle operating costs. Then compared with the ability to pay and the will of the people of the City of Mataram. Then the number of taxi fleet requirements for the City of Mataram will be calculated.

From the results of this study it can be concluded that: 1). there is an excess number of taxi fleets, which is 550 fleet optically, but in reality the current taxi fleet operating based on real conditions in the field is as many as 636 fleets from all operators, 2). 48.75\% of respondents have the ability to pay a tariff of Rp.3,900 / kilometer and the remaining 52.25\% of respondents are forced to use conventional taxis, 3). Current rates are in accordance with government regulations. This can be seen from the calculation of vehicle operating costs (BOK) for the tariff per kilometer is Rp. 4,000 per kilometer while the current tariff is Rp. 3,900, - only a difference of Rp. 100, -

Keywords: ATP, WTP, BOK, Taxi Fleet Needs, Taxi Rates. 


\section{PENDAHULUAN}

\section{Latar Belakang}

Transportasi merupakan bidang kegiatan yang sangat penting dalam kehidupan masyarakat Indonesia. Pentingnya transportasi bagi masyarakat Indonesia disebabkan oleh beberapa faktor antara lain, keadaan geografis Indonesia yang terdiri dari ribuan pulau kecil dan besar, perairan yang terdiri dari sebagian besar laut, sungai dan danau yang memungkinkan pengangkutan dilakukan melalui darat, perairan, dan udara guna menjangkau seluruh wilayah Indonesia

Tidak berbeda halnya dengan Kota Mataram yang pada saat ini daerahnya sedang dalam perkembangan, pembangunan serta peningkatan bagi sarana dan prasrana yang baik, salah satunya adalah peningkatan layanan angkutan umum.

Angkutan umum saat ini yang banyak beroprasi di Kota Mataram adalah Bemo, Taksi, Bus, Engkel, dan lain sebagainya. Salah satu yang popular adalah Taksi. Taksi menurut Peraturan Pemerintah nomor 41 tahun 1993 adalah kendaraan umum dengan jenis mobil penumpang yang di beri tanda khusus dan dilengkapi dengan agrometer.

Dengan berkembangnya Teknologi maka berkembang pula pemikiran untuk menggunakan aplikasi dalam dunia usaha. Salah satunya adalah usaha dalam bidang transportasi. Saat ini sudah muncul layanan angkutan berbasis aplikasi. Dengan munculnya layanan tersebut, maka Taksi Konvensional memiliki pesaing baru. Adanya persaingan tersebut, maka timbulah perselisihan antara Taksi Konvensional dan Taksi berbasis aplikasi. Untuk mengatasi hal tersebut maka pemerintah mengeluarkan berbagai macam regulasi, salah satunya Peraturan Mentri Perhubungan dengan Nomor PM 108 Tahun 2017 tentang Angkutan Orang Dengan Kendaraan Bermotor Umum Tidak Dalam Trayek. Dengan adanya Taksi Berbasis Aplikasi maka sebagian masyarakat di Kota Mataram berpeluang berpindah minat pengguna Taksi Berbasis Aplikasi. Dengan kondisi tersebut maka jumlah armada Taksi Konvensional di Kota Mataram perlu ditinjau ulang

\section{Rumusan Masalah}

Berdasarkan latar belakang di atas dapat dibuat rumusan masalah sebagai berikut:

1. Berapakah kebutuhan armada taksi yang sesuai dengan demand untuk masyarakat di Kota Mataram?

2. Berdasarkan tarif taksi yang ditetapkan saat ini, berapakah tingkat kemampuan membayar dan kemauan membayar masyarakat?

3. Bagaimana pengaruh Biaya Oprasional Kendaraan (BOK) bagi perusahaan taksi dalam menetukan tarif dan jumlah armadamya?

\section{Tujuan dan Manfaat Penelitian}

Adapun tujuan penelitian dari studi ini adalah:

1. Mengetahui banyaknya kebutuhan armada taksi yang sesuai dengan demand untuk masyarakat di Kota Mataram saat ini.

2. Mengevaluasi kesesuaian tarif oprasional taksi ditinjau dari sisi biaya oprasional kendaraan (BOK), ability to pay (ATP), dan willingness to pay (WTP).

3. Mengetahi Biaya Oprasional Kendaraan (BOK) bagi perusahaan taksi dalam menetukan tarif dan jumlah armadanya.

Penelitian ini diharapkan bermanfaat sebagai berikut :

1. Bagi peneliti selanjutnya, dapat menjadi sumber refrensi dalam evaluasi tarif dan jumlah armada angkutan.

2. Bagi dinas atau Instansi-intansi terkait dapat sebagai masukan dalam penentuan kebijakan tarif dan jumlah armada Taksi konvensional di Kota Mataram. 


\section{METODE PENELITIAN}

Penelitian ini dilaksanakan di Kota Mataram, dengan layanan taksi sekitar Ampenan, Sekarbela, Mataram, Selaparang, Cakranegara dan Sandubaya

\section{Penentuan Sampel}

Metode yang digunakan adalah metode stratified proforsional sampling dengan jumlah sampel dari setiap strata sebanding, sesuai dengan proporsi ukurannya. Dalam hal ini digunakan jumlah penduduk dari masing-masing kecamatan yang telah ditentukan sebagai wilayah populasi. 2014)

Penentuan jumlah sampel menggunakan teknik solvin, yaitu dengan menggunakan rumus : (siregar,

$$
\mathrm{n}=\frac{N}{1+N e^{\wedge} 2}
$$

keterangan:

$\mathrm{n}=$ jumlah sampel, 459314 jiwa ( data BPS Kota Mataram tahun2 016)

$\mathrm{N}=$ jumlah populasi

$\mathrm{e}=$ perkiraan tingkat kesalahan (digunakan 5\%)

sehingga, sampel yang akan diambil sebanyak:

$$
\mathrm{n}=\frac{459314}{1+\left(459314 \times 0.05^{\wedge} 2\right)}
$$

$\mathrm{n}=399,651$, dibulatkan menjadi 400 jiwa.

Sedangkan untun sampel survey BOK, penentuan juamlahnya juga digunakan teknik solvin, sehingga sampel yang akan diambil sebanyak:

$$
\begin{aligned}
& =\frac{636}{1+\left(636 \times 0.05^{\wedge} 2\right)} \\
& n=245,59 \text {, dibulatkan menjadi } 246 \text { sampel kendaraan }
\end{aligned}
$$

\section{Jenis dan Sumber Data}

Data primer diperoleh dengan cara wawancara langsaung kepada oprator taksi, supir taksi dan masyarakat pengguna. Terdapat tiga data kelompok data primer yaitu data primer yang akan digunakan untuk analisis BOK, analisis kebutuhan armada, dan data primer yang akan digunakan untuk analisis ATP dan WTP.

Data primer BOK didapat langsung dari operator/penyedia jasa dan sampel dari pengemudi taksi. Dari operator diperoleh data BOK mengenai biaya langsung dan tidak langsung, sedangkan dari pengemudi diperoleh data efektifitas oprasional taksi. Data yang akan diambil dari pengemudi diantaranya sebagai berikut : Kilometer total harian, Kilometer kosong harian, Kilometer isi harian, Kecepatan rata-rata perjalanan, Jumlah operasi selama satu bulan, Frekuensi angkut harian, Gaji/upah dan bonus, Konsumsi bahan bakar harian, Harga taksi, Harga oli, Biaya service (kecil/besar), Biaya pemeriksaan umum, Gaji pegawai, Biaya STNK, Biaya kantor, Jam kerja awak taksi, Jarak perjalanan, Biaya pemeliharaan kantor, Jumlah armada dan Jumlah pengemudi

Untuk analisis kebutuhan armada taksi, diperoleh data dari operator dan driver taksi yang bersangkutan, data-data yang dikumpulkan adalah sebagai berikut: Kilo meter tempuh rata-rata taksi perhari, Frekuensi angkut (rit) per taksi per hari dan Total permintaan taksi melalui telpon per hari

Kemudiaan untuk data dari pengguna taksi diperoleh dari survey kuisioner terhadap masyarakat. berupa: Jumlah penduduk pada lokasi tersurvey, Pedapatan rata-rata pengguna riil taksi, Persentase pendapatan rata-rata pengguna rill taksi dan Intensitas penggunaan taksi dalam sebulan

Untuk data ATP dan WTP dengan pengisian : Jenis pekerjaan, Jumlah anggota keluarga, Besarnya penghasilan responden per bulan, Besarnya penghasilan keluarga responden per bulan,Alokasi pengeluaran untuk biaya transportasi, Jumlah pengeluaran per bulan untuk biaya transporatsi menggunakan jasa angkutan taksi, Intensitas perjalana dan jarak tempuh perjalanan, Kemampuan masyarakat dalam membayar tarif taksi tersebut

Selain itu data yang diperlukan kepada pengguna / penumpang adalah jumlah anggota keluarga, penghasilan per bulan, alokasi pngeluaran untuk kebutuhan transportasi, besar pengeluaran untuk angkutan 
taksi, intensitas perjalanan dan jarak tempuh perjalanan, serta kemampuan masyarakat dalam membayar tarif yang telah diberlakukan.

\section{Analisis Data}

Setelah didapatkan data yang diinginkan baik data primer dan data sekunder dilanjutkan dengan proses analisis. Tahapan yang dilakukan dalam analisis ini adalah:

1).Perhitungan biaya oprasional kendaraan (BOK), 2). Perhitungan Ability To Pay (ATP) dan Willingness To Pay (WTP), 3). Perhitungan jumlah kebutuhan armada taksi dan 4).Penetuan Tarif Taksi Konvensional.

\section{HASIL DAN PEMBAHASAN}

\section{Biaya Operasional Kendaraan (BOK)}

Tabel 1 Hasil Perhitungan Tarif Berdasarkan Perhitungan BOK Operator

\begin{tabular}{|c|c|c|c|c|c|c|c|}
\hline & Kotama & $\begin{array}{l}\text { Lombok } \\
\text { Baru }\end{array}$ & $\begin{array}{l}\text { Lombok } \\
\text { Taksi Utama } \\
\text { (Bluebird } \\
\text { Group) } \\
\end{array}$ & $\begin{array}{l}\text { Lombok Sea } \\
\text { Side Cottage } \\
\text { (Bluebird } \\
\text { Group) } \\
\end{array}$ & $\begin{array}{l}\text { Rangga } \\
\text { Rizki } \\
\text { Pratama }\end{array}$ & $\begin{array}{l}\text { Lendang } \\
\text { Karun } \\
\text { (Express) }\end{array}$ & Rata-rata \\
\hline \multicolumn{8}{|c|}{ BIAYA LANGSUNG } \\
\hline $\begin{array}{l}\text { Biaya bunga } \\
\text { Modal }\end{array}$ & 451.90476 & 225.95238 & 967.5611681 & 967.5611681 & 689.4826 & 254 & 592.7437 \\
\hline Penyusutan & 669.48854 & 334.74427 & 112.8821363 & 112.8821363 & 80.43963 & 376.2963 & 281.1222 \\
\hline $\begin{array}{l}\text { Gaji dan bonus } \\
\text { awak }\end{array}$ & 2033.3333 & 833.33333 & 920.8066298 & 920.8066298 & 656.1654 & 1600 & 1160.741 \\
\hline Biaya BBM & 720.2 & 476.66667 & 474.0331492 & 474.0331492 & 337.7953 & 572 & 509.1214 \\
\hline Ban & 48 & 48 & 112.9943503 & 112.9943503 & 112.9944 & 48 & 80.49718 \\
\hline Servis kecil & 86.832 & 100 & 118.6440678 & 118.6440678 & 118.6441 & 100 & 107.1274 \\
\hline Servis besar & 67.5 & 67.5 & 63.75 & 63.75 & 63.75 & 67.5 & 65.625 \\
\hline $\begin{array}{l}\text { Biaya overhoule } \\
\text { mesin }\end{array}$ & 36.418815 & 40 & 409.8667286 & 409.8667286 & 409.8667 & 40 & 224.3365 \\
\hline Cuci kendaraan & 38.095238 & 38.095238 & 9.523809524 & 9.523809524 & 9.52381 & 38.095238 & 23.80952 \\
\hline $\begin{array}{l}\text { Biaya } \\
\text { pemeliharaan } \\
\end{array}$ & 94.5 & 94.5 & 142.3728814 & 142.3728814 & 142.3729 & 94.5 & 118.4364 \\
\hline STNK & 32.137593 & 30.864198 & 30.6936771 & 30.6936771 & 21.87227 & 37.037037 & 30.54974 \\
\hline KIR & 2.7777778 & 2.7777778 & 0.941619586 & 0.941619586 & 0.94162 & 2.7777778 & 1.859699 \\
\hline Retribusi & 111.11111 & 55.555556 & 55.24861878 & 55.24861878 & 39.37008 & 66.666667 & 63.86677 \\
\hline Asuransi & 86.874506 & 43.437253 & 41.85105203 & 41.85105203 & 29.82299 & 48.829148 & 48.77767 \\
\hline JUMLAH & 4479.1737 & 2391.4267 & 3461.169888 & 3461.169888 & 2713.042 & 3345.7022 & 3308.614 \\
\hline \multicolumn{8}{|c|}{ BIAYA TIDAK LANGSUNG } \\
\hline Biaya selain awak & 1.7361111 & 0.8439429 & 0.959177409 & 0.959177409 & 0.512631 & 2.1412037 & 1.192041 \\
\hline $\begin{array}{l}\text { Biaya } \\
\text { pengelolaan } \\
\text { kantor } \\
\end{array}$ & 170.48842 & 168.63426 & 86.32596685 & 86.32596685 & 120.9058 & 336.11111 & 161.4653 \\
\hline JUMLAH & 172.22453 & 169.4782 & 87.28514426 & 87.28514426 & 121.4184 & 338.25231 & 162.6573 \\
\hline TOTAL & 4651.3982 & 2560.9049 & 3548.455033 & 3548.455033 & 2834.46 & 3683.9545 & 3471.271 \\
\hline $\begin{array}{l}\text { Tarif Awal (Flag } \\
\text { Fall) }\end{array}$ & 5500 & 5500 & 5500 & 5500 & 5500 & 5500 & 5500 \\
\hline $\begin{array}{l}\text { Tarif per } \\
\text { Kilometer }\end{array}$ & 4993.764 & 3329.308 & 4150.623 & 4150.623 & 3309.5 & 4036.82 & 3995.106 \\
\hline $\begin{array}{l}\text { Tarif Tunggu per } \\
\text { Jam }\end{array}$ & 40000 & 40000 & 40000 & 40000 & 40000 & 40000 & 40000 \\
\hline
\end{tabular}

Sumber : Hasil Perhitungan 
Dari hasil perhitungan BOK diatas didapat besar tarif per kilometer yang dibebankan kepada penumpang menurut operator Koperasi Taksi Mataram (Kotama) adalah Rp. 5.000,-/km, sedangkan untuk tarif buka pintu/tarif awal (flag fall) sebesar Rp. 5.500,- dan tarif tunggu sebesar Rp 40.000,-. Hal ini menunjukan bahwa tarif/km yang telah berlaku saat ini jauh diatas tarif yang sehausnya dapat diberlakukan yaitu sebesar Rp. 3.900,-. Untuk tarif buka pintu dan tarif tunggu diambil dari hasil perhitungan Peraturan Gubernur Nusa Tenggara Barat Nomor 19 Tahun 2005 tentang Penetapan Tarif Angkutan Taksi di Provinsi Nusa Tenggara Barat.

\section{Ability To Pay (ATP)}

Perhitungan ATP dapat dilakukan dengan menghitung beberapa parameter yang bersangkutan dengan data responden. Parameter-parameter tersebut antara lain:

Jumlah anggota keluarga responden, Total pendapatan responden per bulan, Biaya alokasi transportasi responden per bulan, Intensitas penggunaan taksi per bulan dan Jarak perjalanan responden menggunakan taksi dengan pormulasi :

$$
\mathrm{ATP}=\frac{I x \cdot P p \cdot P t}{T r}
$$

Keterangan :

$\mathrm{ATP}=$ Daya beli responden $(\mathrm{Rp} / \mathrm{kilometer}), \mathrm{Ix}=$ Jumlah penghasilan responden per bulan $(\mathrm{Rp} / \mathrm{bulan})$,

$\mathrm{Pp}=$ persentase budget untuk transportasi per bulan dari total penghasilan, $\mathrm{Pt}=$ Persentase alokasi biaya transportasi yang digunakan untuk angkutan taksi, $\operatorname{Tr}=$ Total panjang perjalanan responden per bulan $(\mathrm{km} / \mathrm{bulan})$

\section{Willingness To Pay (WTP)}

Willingness to pay adalah persepsi responden terhadap tarif taksi per kilometer yang sesuai dibandingkan dengan pelayanan yang diberikan, sehingga perhitungan besarnya WTP didasarkan data persepsi responden atas tarif yang berlaku (rupiah/kilometer). Setelah dianalisa dari 400 kuisioner, WTP tertinggi terdapat pada harga Rp 12.000,- per kilometer sedangkan untuk WTP terendah adalah Rp 833,33,per kilometer. Persepsi tarif dari masing-masing responden berbeda-beda, hal ini disebabkan perbedaan latar belakang dari masing-masing responden sehingga responden memilih tariff yang dianggap sesuai dengan kemampuannya.

Dari hasil ATP dan WTP Kota Mataram, persentase responden yang mau membayar untuk tarif yang berlaku saat ini hanya 52,25\% yaitu sebanyak 209 responden. Sedangkan untuk WTP responden terhadap tarif yang berlaku saat ini sebanyak 36,75\% setara dengan 147 responden. Ini menunjukan bahwa tarif yang berlaku saat ini masih jauh berada di atas kemampuan masyarakat Kota Mataram. Namun untuk kemauan masyarakat menggunakan taksi sudah di atas 50\%. Grafik di atas membuktikan bahwa $48,75 \%$ responden merasa terpaksa menggunakan taksi sebagai transportasinya.

Sementara itu, jika ditarik garis berdasarkan perhitungan BOK kemampuan membayar responden menurun 1 responden menjadi 36,5\% setara dengan 146 responden. Sedangkan untuk kemauan membayar responden menurun 1 responden menjadi 52\%, yang artinya bahwa masyarakat mau menggunakan taksi dengan tarif berdasarkan hasil perhitungan BOK. Hal ini menunjukan bahwa pada tarif tersebut responden merasa pantas untuk membayar sesuai dengan pelayanan yang diberikan. Dan sejumlah $48 \%$ responden merasa terpaksa menggunakan taksi.

\section{Analisis Kebutuhan Jumlah Armada Taksi}

Dalam menganalisa kebutuhan armada berdasarkan supply dan demand berdasarkan keputusan menteri KM no. 35 tahun 2003 bahwa evaluasi kebutuhan taksi suatu kota dilakukan apabila tingkat penggunaan taksi sekurang kurangnya $60 \%$ atau dengan kata lain apabila pelayanan taksi (supply) dibandingkan dengan pelayanan (demand) yang direpresentatifkan dengan tingkat penggunaan kendaraan kurang atau sama dengan 60\%. Sehingga untuk analisa kebutuhan taksi di wilayah Kota Mataram menghasilkan rasio supply dan demand sebagai berikut 
Dari hasil perhitungan diatas didapatkan hasil perlu adanya evaluasi terhadap jumlah taksi yang beroperasi karena tingkat penggunaan taksi berdasarkan supply dan deman ada beberapa penyedia yang kurang dari $<60 \%$ sehingga perlu dievaluasi jumlah armadanya

Tabel 2 Hasil Perhitungan Analisis Jumlah Armada

\begin{tabular}{|c|c|c|c|c|c|c|c|c|c|}
\hline No & $\begin{array}{c}\text { Nama } \\
\text { Perusaha } \\
\text { an }\end{array}$ & $\begin{array}{l}\text { Banyak } \\
\text { (Unit) }\end{array}$ & $\begin{array}{c}\mathrm{Km} \\
\text { tempuh } \\
\text { rata-rata } \\
\text { per hari } \\
\text { per taksi }\end{array}$ & $\begin{array}{c}\text { Frekuensi } \\
\text { angkut } \\
\text { untuk } \\
\text { satu } \\
\text { armada }\end{array}$ & \begin{tabular}{|c|} 
Total \\
perminta \\
an taksi \\
(by call) \\
dalam \\
satu hari \\
\end{tabular} & $\begin{array}{c}\text { Supply- } \\
\text { Demand Rasio } \\
\text { (SD Rasio) \% }\end{array}$ & $\begin{array}{c}\text { Tingkat } \\
\text { Penggunaan } \\
\text { Kendaraan }\end{array}$ & & Ket \\
\hline 1 & $\begin{array}{c}\text { Kotama } \\
\text { (Koperasi } \\
\text { Taksi } \\
\text { Mataram }\end{array}$ & 80 & 90 & 2 & 120 & 0.67 & 33.3 & $<60 \%$ & $\begin{array}{l}\text { Butuh } \\
\text { Penyesuaian } \\
\text { Armada }\end{array}$ \\
\hline 2 & \begin{tabular}{|c|} 
Rangga \\
Rzki \\
Pratama \\
\end{tabular} & 40 & 254 & 4 & 160 & 0.25 & 75.0 & $>60 \%$ & $\begin{array}{c}\text { Tidak } \\
\text { Dibutuhkan }\end{array}$ \\
\hline 3 & $\begin{array}{c}\text { Koperasi } \\
\text { Serba } \\
\text { Usaha } \\
\text { Lombok }\end{array}$ & $\begin{array}{l}10 \\
26 \\
\end{array}$ & 180 & 2 & 80 & 0.45 & 55.0 & $<60 \%$ & $\begin{array}{c}\text { Butuh } \\
\text { Penyesuaian } \\
\text { Armada }\end{array}$ \\
\hline 4 & $\begin{array}{c}\text { Lendang } \\
\text { Karun } \\
\text { (Express) }\end{array}$ & 150 & 150 & 5 & 200 & 0.75 & 25.0 & $<60 \%$ & $\begin{array}{c}\text { Butuh } \\
\text { Penyesuaian } \\
\text { Armada } \\
\end{array}$ \\
\hline 5 & \begin{tabular}{|c|} 
Lombok \\
Taksi \\
Utama \\
(Blue Bird \\
Group) \\
\end{tabular} & 200 & \multirow{2}{*}{181} & \multirow{2}{*}{13} & \multirow{2}{*}{3800} & \multirow{2}{*}{0.087} & \multirow{3}{*}{91.3} & \multirow{2}{*}{$>60 \%$} & \multirow{2}{*}{$\begin{array}{c}\text { Tidak } \\
\text { Dibutuhkan }\end{array}$} \\
\hline 6 & $\begin{array}{c}\text { Lombok } \\
\text { Sea Sde } \\
\text { Cottage } \\
\text { (Blue Bird } \\
\text { Group) }\end{array}$ & 130 & & & & & & & \\
\hline & Jumlah & 636 & & & & & & & \\
\hline
\end{tabular}

Dari hasil perhitungan di atas didapatkan hasil perlu adanya evaluasi terhadap jumlah taksi yang beroperasi karena tingkat penggunaan taksi berdasarkan supply dan deman ada beberapa penyedia yang kurang dari $<60 \%$ sehingga perlu dievaluasi jumlah armadanya

\section{SIMPULAN DAN SARAN}

\section{Simpulan}

Dari hasil penelitian dapat disimpulkan bahwa :

1). terjadi kelebihan jumlah armada taksi, yang optmal adalah 550 armada, tapi kenyataan Armada taksi yang beroprasi saat ini berdasarkan kondisi rill di lapangan adalah sebanyak 636 armada dari semua operator,

2). $48,75 \%$ responden mempunyai kemampuan membayar tarif yang nilainya sebesar Rp.3.900/kilometer dan sisanya 52,25\% responden karena terpaksa menggunakan taksi konvensional,

3). Tarip yang berlaku saat ini sudah sesuai dengan peraturan pemerintah. Hal ini dilihat dari perhitungan biaya operasional kendaraan (BOK) untuk tarif per kilometer adalah Rp 4.000,- per kilometer sedangkan tarif yang berlaku saat ini adalah Rp 3.900,- hanya selisih Rp 100,-

\section{Saran-saran}

Dari hasil penelitian ini dapat disarankan sebagai berikut:

1. Penetapan tarif yang berlaku sesuai dengan perhitungan Dishubkominfo perlu dipertimbangkan untuk kenaikan secara berkala yang tentunya dengan mempertimbangkan biaya operasional operator dan kemampuan masyarakat yang pendapatannya di bawah pendapatan rata-rata pengguna taksi.

2. Penyediaan angkutan umum dan sewa khusus lain sebagai kompetitor angkutan taksi perlu dipertimbangkan untuk keefektifan jumlah armada yang ada, contohnya adalah angkutan taksi berbasis aplikasi.. 


\section{DAFTAR PUSTAKA}

Arsari A., L., F. 2016. Evaluasi Kesesuaian Tarif dan Kebutuhan Armada Taksi Di Kabupaten Sumbawa Berdasarkan ATP dan WTP. Sikripsi Program Studi Teknik Sipil Universitas Mataram.

Giatman, M. 2007. Ekonomi Teknik. PT . Raja Grafindo Persada: Jakarta

Hotmaida, B (1999), Analisis Ability To Pay dan Willingness To Pay Tarif Angkutan Umum Kota (Studi Kasus : Kotamadia Medan), Tesis Magister, Bidang Khusus Rekayasa Transportasi Program Magister Teknik Sipil Program Pasca Sarjana ITB, Bandung

Keputusan Direktur Jenderal Perhubungan Darat Nomor 687 tahun 2002 Tentang Pedoman Teknis Penyelengaraan Angkutan Penumpang Umum Di Wilayah Perkotaan Dalam Trayek Tetap dan Teratur.

Keputusan Menteri Nomor 35 Tahun 2003 Tentang Penyelengaraan Angkutan Orang di Jalan dengan Kendaraan Umum

Miro, F. 2012. Pengantar Sistem Transportasi. Erlangga: Jakarta

Munawar, A., 2005, Dasar-Dasar Teknik Transportasi, Cetakan Ke-1, Penerbit Beta Offset, Yogyakarta

Peraturan Pemerintah Nomor 41 tahun 1993 Tentang Angkutan Jalan

Peraturan Menteri Perhubungan Republik Indonesia Nomor PM 108 tahun 2017

Tamin, O.Z., Rahman, H., Kusumawati, A., Munandar, A.S., Setiadji, B.H. 1999. Evaluasi Tarif Angkutan Umum dan Analisis "Ability to Pay" (ATP) dan "Willingnss to Pay (WTP) Di DKI Jakarta. Jurnal Transportasi, ISSN: 1411-2442 Vol 1, No 2, Tahun I, Desember 1999

Undang-undang Nomor 22 Tahun 2009 Tentang Lalu Lintas dan Angkutan Jalan

Vuchic, Vukan R., 1981, Urban Public Transportation; System Ana Technology, Prentice Hall, Inc, Englewood Cliffs, New Jersey, USA

Warpani Suwardjoko, 2002, Pengelolaan Lalu Lintas dan Angkutan Jalan, Institut Teknologi Bandung, Bandung 